\title{
Thioredoxin-Interacting Protein as a Novel Potential Therapeutic Target in Diabetes Mellitus and Its Underlying Complications
}

This article was published in the following Dove Press journal: Diabetes, Metabolic Syndrome and Obesity: Targets and Therapy

\author{
Dawit Zewdu Wondafrash (D) $^{1}$ \\ Asmelash Tesfay Nire'a ${ }^{2}$ \\ Gebrehiwot Gebremedihn \\ Tafere \\ Desilu Mahari Desta ${ }^{3}$ \\ Demoze Asmerom Berhe $\mathbb{I D}^{4}$ \\ Kaleab Alemayehu Zewdie (iD) ${ }^{\prime}$ \\ 'Department of Pharmacology and \\ Toxicology, School of Pharmacy, Mekelle \\ University, Mekelle, Ethiopia; \\ ${ }^{2}$ Pharmacology and Toxicology Research \\ and Course Unit, Department of \\ Pharmacy, Axum University, Axum, \\ Ethiopia; ${ }^{3}$ Clinical Pharmacy Research \\ and Course Unit, School of Pharmacy, \\ Mekelle University, Mekelle, Ethiopia; \\ ${ }^{4}$ Department of Medicinal Chemistry, \\ School of Pharmacy, Mekelle University, \\ Mekelle, Ethiopia
}

Correspondence: Dawit Zewdu Wondafrash

Department of Pharmacology and

Toxicology, School of Pharmacy, Mekelle

University, P.O. Box: I87I, Mekelle,

Ethiopia

$\mathrm{Tel}+251910127356$

Email davaniye@gmail.com

\begin{abstract}
Diabetes mellitus (DM) is a common metabolic disorder which is characterized by a persistent increment of blood glucose. Globally, DM affects millions of people and the prevalence is increasing alarmingly. The critical step in the pathophysiology of DM is the loss of $\beta$ cells of the pancreas, which are responsible for the secretion of insulin. Thioredoxin-interacting protein (TXNIP) is among the factors that control the production and loss of the pancreatic $\beta$ cells. TXNIP is an $\alpha$-arrestin that can bind and inhibit thioredoxin (the antioxidant protein) which is produced in the pancreatic islet after glucose intake. Numerous studies illustrated that elevated TXNIP levels were found to induce $\beta$-cell apoptosis; whereas TXNIP deficiency protects against type I and type II diabetes by promoting $\beta$-cell survival. Nowadays, TXNIP depletion is becoming a key factor in pancreatic $\beta$-cell survival enhancement. In the present review, targeting TXNIP is found to be relevant as a unique therapeutic opportunity, not only to improve insulin secretion and sensitivity, but also ameliorating the long term microvascular and macrovascular complications of the disease. Thus, TXNIP inhibitors that could reduce the expression and/or activity of TXNIP to non-diabetic levels are promising agents to halt the alarming rate of diabetes and its related complications.
\end{abstract}

Keywords: diabetes mellitus, thioredoxin, TXNIP, TXNIP modulators, verapamil

\section{Introduction}

Diabetes mellitus (DM) is a common metabolic disorder characterized by a persistent increment of blood glucose ${ }^{1}$ caused due to defects in insulin secretion and/or action. $^{2} \mathrm{DM}$ is a common public health problem that affects millions of people of all ages, gender, race and ethnic groups all over the world. ${ }^{3}$ The prevalence of DM is increasing rapidly in the world at an alarming rate. ${ }^{4}$ In the past decades, the epidemicity of the disease is growing and the incidence was increased by $50 \%{ }^{5}$

According to the International Diabetes Federation (IDF), DM is the third highest risk factor following elevated blood pressure and tobacco use for premature mortality globally. It accounts about 4.0 million (10.7\%) of global all-cause mortality among people aged 20-79 years, which is higher than the combined number of death reports in three major infectious diseases $(1.1,1.8$ and 0.4 million deaths from human immunodeficiency virus/acquired immunodeficiency syndrome (HIV/ AIDS, tuberculosis, and malaria respectively). ${ }^{6}$

In 2015, IDF estimated that diabetic patients in Africa will be projected to 34.2 million in 2040. Furthermore, it was forecasted that Africa spends $7 \%$ of its healthcare budget on diabetes. In Africa, more than $50 \%$ of adults with DM were live in most 
populous countries such as Nigeria, Democratic Republic of Congo, South Africa, and Ethiopia. ${ }^{7}$ Nowadays the rising magnitude of non-communicable diseases was seen in Ethiopia including DM. The nation is among the top four countries with the highest adult diabetic populations in SubSaharan Africa. ${ }^{2}$

Based on different pathophysiologic processes diabetes mellitus is classified mainly into three categories. ${ }^{8}$ Type I diabetes mellitus (TIDM), is the first sub-type of DM which is also called insulin-dependent, which is caused by an autoimmune reaction, in which the immune system invades the insulin-secreting pancreatic $\beta$-cells. ${ }^{9}$ Type II diabetes (TIIDM) is the second sub-type of DM which is the most dominant, comprising around $85 \%$ of diabetes cases, ${ }^{10}$ that is denoted by impairment in insulin secretion from pancreatic $\beta$-cells and/or insulin sensitivity. ${ }^{4,11}$

Moreover, gestational diabetes mellitus (GDM), is another sub-type DM that appears at the period of pregnancy that can lead to serious health risks both to the mother and her infant and it could also increase the risk of developing TIIDM later in life. ${ }^{4,12}$ Untreated DM is associated with the development of various acute and long-term complications ${ }^{13}$ including macrovascular complications which lead to stroke, heart attack and circulation problems in the lower limbs and microvascular complications predisposing to problems in the eyes (retinopathy), kidneys (nephropathy), feet, and nerves damage (neuropathy). ${ }^{5}$

There are different treatment modalities for DM and documented evidence of the critical role of $\beta$-cell death in the development of diabetes is available. However, little is known about the prevention and enhancing the life span of endogenous $\beta$-cells mass, which have a critical role in diabetes pathogenesis. Therefore, novel approaches that could promote pancreatic $\beta$-cell survival and protect against apoptotic $\beta$-cell loss to prevent diabetes, are urgently in need. ${ }^{14}$

\section{Thioredoxin Interacting Protein}

Thioredoxin-interacting protein (TXNIP), also known as thioredoxin-binding protein 2 (TBP-2)/vitamin D3up-regulated protein 1 (VDUP1), is an $\alpha$-arrestin that can bind to and inhibit thioredoxin (the antioxidant protein). It was initially identified as a vitamin D3 target gene in the cancer cell line. The $\alpha$-arrestins are known as multifunctional scaffolding proteins involved in protein-protein interactions that mediate a wide array of signaling processes. ${ }^{15}$ TXNIP is expressed in metabolically important sites like adipose tissue, liver, and skeletal muscles. It is also the main regulator of glucose balance in our system. ${ }^{16}$ TXNIP directly binds to two cysteine moieties of the only reduced form of thioredoxin at the active catalytic site of thioredoxin, consequently results blocking its reducing potential. This disulfide exchange reaction between reduced thioredoxin and TXNIP is crucial for the interaction between the two proteins. TXNIP undergoes a structural reorganization upon binding to thioredoxin which involves the formation of a de novo TXNIP cysteine 247thioredoxin cysteine 32 disulfide bond. ${ }^{17}$

Cellular redox balance (reduction/oxidation) is strongly regulated by the activity of numerous antioxidant systems including thioredoxin, glutathione, and glutaredoxin systems. ${ }^{18}$ Oxidative stress can be triggered by an alteration in balance from the normal reduced cellular environment to a state of excessive reactive oxygen species (ROS) generation, which is due to an enhanced ROS generation and/or decrease in the mechanisms that reduce ROS. ${ }^{19}$

The thioredoxin system plays an important role in maintaining a reduced environment in the cell composed of nicotinamide adenine dinucleotide phosphate (NADPH; as the electron donor), thioredoxin reductase (TXNR), and thioredoxin, that defends cells from oxidative stress through its disulfide reductase activity. ${ }^{20}$ In mammalian cells, there are two isoforms of thioredoxin called thioredoxin1 (TXN1) and thioredoxin 2 (TXN2). TXN1 is a 12-kilo Dalton ubiquitous protein that has disulfide-reducing activity, mainly located in the cytosol but also translocate to the nucleus and can be secreted from cells under certain circumstances; whereas TXN2 is located only in mitochondria. ${ }^{11}$ Oxidized proteins produced by ROS are reduced by the oxidoreductase action of thioredoxin. Oxidized thioredoxin generated in the process is subsequently reduced by NADPH-dependent TXNR. TXNIP binds and negatively modulates the activity of thioredoxin, thereby influencing the cellular redox balance (Figure 1). ${ }^{17,21}$

\section{TXNIP/Thioredoxin Interaction and Its Cellular Effects}

Thioredoxin interacting protein binds and inhibits TXN1 in the cytoplasm and thereby affects the ability of TXN1 to reduce oxidized proteins, resulting in oxidative stress and increased susceptibility to apoptosis. ${ }^{22}$ TXNIP translocates to the mitochondria where it interacts with mitochondrial TXN2, which is part of the mitochondrial antioxidant defense mechanism. In the mitochondria, TXNIP inhibits the activity of apoptosis signal-regulating kinase 1 (ASK-1) 


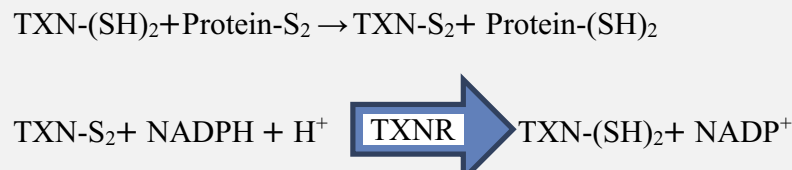

Figure I Thioredoxin mediated redox reaction.

Abbreviations: $\mathrm{H+}$, Hydrogen; NADPH, Nicotinamide adenine dinucleotide phosphate; S2, Disulphide; SH, Disulphide hydride; TXN, Thioredoxin; TXNR, Thioredoxin reductase.

by competing with ASK-1 to bind with TXN-2 resulting in the release of ASK-1 from its inhibition by TXN2 and then allowing for phosphorylation and activation of ASK-1 and initiation of the apoptotic signaling cascade in pancreatic $\beta$-cells. ${ }^{17}$

Furthermore, this leads to cytochrome c (Cyt c) release from the mitochondria, cleavage of caspase-3, and apoptosis. TXNIP has also been found to be localized in the nucleus and promotes $\beta$-cell apoptosis by increasing the expression of pro-apoptotic micro-ribonucleic acids (miR204, miR-200). This microRNAs down-regulate the expression of target genes including important $\beta$-cell transcription factors such as musculoaponeurotic fibrosarcoma oncogene homolog A (MafA), which results in reduced insulin transcription and impaired $\beta$-cell function. ${ }^{22}$

\section{TXNIP in the Pathogenesis of Diabetes Mellitus}

Despite the differential mechanism for the pathogenesis of TIDM and TIIDM, oxidative stress is frequently related to the pathogenesis of the disease. ${ }^{17}$ This is due to pancreatic $\beta$-cells are uniquely susceptible to oxidative stress as a result of their low expression level of antioxidant enzymes. $^{22}$ It has been known that low levels of cellular ROS are required for cellular signaling while the chronic excessive generation of ROS aggravate insulin sensitivity in skeletal muscle and disrupt $\beta$-cell function and survival, suggesting that an optimal balance of cellular redox regulation is critical for the pathogenesis of both TIDM and TIIDM. $^{11}$

Synthesis and release of adequate amounts of insulin by pancreatic $\beta$-cells are required for keeping the normal glucose level in the body. Indeed, $\beta$-cell malfunction and reduced insulin production are key factors in the pathogenesis of diabetes, despite the growing worldwide diabetes epidemic, the molecular mechanisms involved in this disease process have only begun to be discovered. ${ }^{23}$

Recently, TXNIP has been identified as a vital factor in $\beta$-cell biology. In particular, it was shown that $\beta$-cell
TXNIP was up-regulated in diabetes; whereas TXNIP deficiency protected against TIDM and TIIDM by preventing $\beta$-cell apoptosis and increasing the whole-pancreas $\beta$ cell mass. $^{23}$

Beta-cell TXNIP expression is highly triggered by glucose and is increased in diabetes as well as in response to endoplasmic reticulum (ER) stress, and this induction is caused at the transcriptional level by carbohydrate response element-binding protein (ChREBP) and at the posttranscriptional level by a reduction in miR-17 and is controlled by a number of additional factors. TXNIP, in turn, inhibits thioredoxin function and promotes oxidative stress and $\beta$-cell death. Besides, by modulating the expression of distinct microRNAs (miR-204 and miR-124a) and with that the expression of their target genes (MafA and forkhead box A2 (FoxA2)) TXNIP prevents insulin transcription while inducing islet amyloid polypeptide (IAPP) transcription and again via ChREBP. $^{22}$

\section{TXNIP in the Pathogenesis of Diabetes Mellitus Complications}

Oxidative stress is considered as a vital triggering factor in the progression of diabetic complications. It is not only the generation of ROS increased in diabetes, but also the activity of the antioxidant system fails. Several studies on diabetes and the thioredoxin system revealed that levels of TXNIP, as an endogenous inhibitor of thioredoxin, are increased in hyperglycemia. These increased TXNIP levels then inhibit the function of thioredoxin, inducing increased levels of freely diffusible molecular hydrogen peroxide which contributes to oxidative stress. ${ }^{24-26}$

\section{Diabetic Vascular Dysfunction}

Endothelial dysfunction is considered as the primary sign of cardiovascular disease, which is one of the major complications of DM. ${ }^{27}$ Vascular complications are a major cause of diabetes-related morbidity and mortality. TXNIP is overexpressed in the glucose inducible gene of both humans and diabetic animals, which is due to the carbohydrate response. 
It is a key element in the promotion of angiogenesis. TXNIP regulates the activity of vascular endothelial growth factor (VEGF), the major angiogenic cytokine. ${ }^{28}$

TXNIP played a significant role in the pathogenesis of impaired angiogenesis in diabetes. This is due to high glucose-induced overexpression of TXNIP leads to impairment in endothelial cell function, decreased production of nitric oxide (NO), reducing VEGF production and sensitivity to VEGF action, concurrent with increased expression of ROS and vascular cell adhesion molecule 1 (VCAM-1). ${ }^{29}$ Furthermore, it was demonstrated that targeted knockdown/ silencing of TXNIP reverses the high glucose-induced impairment of endothelial cell angiogenic function, VEGF production, and sensitivity to VEGF action. ${ }^{28}$

\section{Diabetic Retinopathy}

Diabetic retinopathy (DR) arises as a consequence of an increasing incidence of DM, which is the most common cause of blindness (attributed to $2.6 \%$ of global blindness) among the adult-age population in the developed and developing countries. This complication is expected to increase in the coming decades because of its limited treatment options, complex pathogenesis and lack of safe delivery systems to target the retina. ${ }^{30,31}$

DR is a common microvascular dysfunction which is characterized by cellular capillary formation, inner blood-retinalbarrier breakdown, endothelial dysfunction, pericyte loss, thickening of the capillary basement membrane and microaneurisms (non-proliferative diabetic retinopathy). Finally, it will lead to the formation of leaky blood vessels and new fragile and end up with proliferative diabetic retinopathy and blindness. $^{32}$

TXNIP is pro-inflammatory, pro-oxidative stress and pro-apoptotic protein which is strongly induced due to a higher level of glucose in retinal cells (retina endothelial cells, Mueller cells, and pericyte cells, and mediates). ${ }^{32,33}$ The retina is a unique organ with its high concentrations of polyunsaturated fatty acids and high oxygen demand. Therefore, retina and its vasculature are more vulnerable to oxidative stress and several lines of evidence supported that increased oxidative stress as the main reason for retinal inflammation in diabetic patients. ${ }^{34,35}$

TXNIP causes DR via initiation of retinal inflammation both at posttranscriptional and transcriptional levels. At post-transcriptional levels, it acts as a direct activator of nod-like receptor protein 3-inflammasome, which is a component of the innate immune system responsible for initiating the inflammatory response. At transcriptional levels, TXNIP results in activation of the nuclear factor $\kappa \mathrm{B}(\mathrm{NF \kappa B})$ pathway, which leads to pro-inflammatory cytokine expression. ${ }^{36}$

\section{Diabetic Nephropathy}

Diabetic nephropathy (DN), is also one of the microvascular complications of DM. It is the most frequent cause of renal disease in developed countries. DN accounts for almost onethird of all cases that lead to renal disease and, with the global "epidemic" of diabetes, has become a major health burden. ${ }^{37}$ In DN, hyperglycemia contributes to the morphologic alterations of the glomerular filtration barrier and loss of podocytes, ultimately leading to impairment of renal filtration. Although chronic hyperglycemia is the major cause, the clear molecular pathogenesis of DN remains unclear. ${ }^{38}$

Among many pathogenic factors, excessive production of ROS is thought to be a major contributor. The presence of excess ROS leads to the oxidation of proteins, deoxyribonucleic acid, and lipids, consequently deranging their configuration and function. ${ }^{39}$ More recently, the role of TXNIP in the pathogenesis of DN has been examined and TXNIP induces oxidative stress and increases extracellular matrix production leading to the progression of DN. Thus, inhibition of TXNIP may be beneficial in the management of diabetic nephropathy. ${ }^{40}$

\section{TXNIP Modulators as Novel Drug Therapy for Diabetes Mellitus}

TXNIP has attracted great consideration due to its various functions impacting several features of energy metabolism. Many studies proposed that interventions intended to modulate the activity of TXNIP might be beneficial in the prevention/management/decreasing the progression of $\mathrm{DM} .{ }^{4-43}$ Pancreatic $\beta$-cell loss through apoptosis is the main factor in the pathogenesis of both TIDM and TIIDM. ${ }^{14}$ As a result, targeting TXNIP as a novel therapeutic target and use of TXNIP inhibitors have the potential to become powerful therapeutic agents for the management of DM. ${ }^{17}$

\section{Verapamil}

Verapamil, a non-dihydropyridine calcium channel blocker, is used in the management of hypertension, angina, and tachyarrhythmia, particularly atrial fibrillation. ${ }^{41}$ However, recent preclinical and clinical data have suggested that the drug has a role in preventing pancreatic $\beta$-cell loss in diabetics by inhibiting TXNIP expression. ${ }^{44}$ Based on several reports, verapamil effectively lowers $\beta$-cell TXNIP expression in rodent 
$\beta$-cells and islets as well as in human islets. This effect is due to a decrease in intracellular free calcium by blocking the L-type calcium channels and leading to inhibition of TXNIP transcription. Tissues with high expression of L-type calcium channels, such as $\beta$ - cells, are therefore most likely to benefit from the resulting TXNIP inhibition. ${ }^{45}$

In a study done on a wild-type male C57BL/6 mice rendered diabetic by streptozotocin to test if verapamil could reduce TXNIP levels, the results demonstrated that about $80 \%$ reduction in TXNIP levels in isolated islets of verapamil-treated animals compared with control mice. ${ }^{46}$ In addition, several human studies reveal that verapamil can decrease TXNIP expression in diabetic patients as shown in Table 1 below.

\section{Other TXNIP Modulators for Diabetes Mellitus}

There are experimental studies regarding the therapeutic role of different TXNIP modulators in diabetes mellitus which are presented in Table 2.

\section{TXNIP Modulators for Diabetes Mellitus Complications}

There are various TXNIP modulators which are potential therapeutic agents for some complications of diabetes mellitus as summarized in Table 3 .

\section{Conclusion and Future Prospects}

In the present review, targeting TXNIP is found to be relevant which offers a unique therapeutic opportunity in the management of diabetes mellitus as well as in the prevention of its long term complications by enhancing the secretion and sensitivity of insulin. Thus, TXNIP inhibitors that could reduce the expression and/or activity of TXNIP to non-diabetic levels are promising agents to stop the alarming rate of diabetes prevalence and its underlying complications. Further preclinical and clinical studies are indispensable to confirm the detailed relevance of TXNIP, and thereby discovering and developing promising agents that could counter the current worldwide diabetic induced public health crisis.

\section{Abbreviations}

ASK-1, Apoptosis signal regulating kinase 1; ChREBP, Carbohydrate response element binding protein; DR, Diabetic retinopathy; DN, Diabetic nephropathy; IDF, International diabetes federation; NLRP3, Nucleotide binding and oligomerization domain-like receptor family pyrin domain-containing 3; ROS, Reactive oxygen species; TIDM, Type I diabetes mellitus; TIIDM, Type II diabetes mellitus; TXN1, Thioredoxin 1; TXN2, Thioredoxin 2; TXNR, Thioredoxin reductase; TXNIP, Thioredoxin interacting protein; VEGF, Vascular endothelial growth factor.

Table I TXNIP Mediated the Effect of Verapamil in Clinical Studies

\begin{tabular}{|c|c|c|c|}
\hline Study Design & Method and Intervention & Treatment Outcome & References \\
\hline $\begin{array}{l}\text { Population-based cohort } \\
\text { study }\end{array}$ & $\begin{array}{l}\text { Two groups (individuals taking oral verapamil } \\
\text { and other oral calcium channel blockers were } \\
\text { compared). In each group, } 4930 \text { patients were } \\
\text { evaluated. }\end{array}$ & $\begin{array}{l}\text { A decreased incidence of TIIDM was reported } \\
\text { in patients taking verapamil. This effect of } \\
\text { verapamil may derive from its ability to inhibit } \\
\text { the expression of TXNIP. }\end{array}$ & 47 \\
\hline $\begin{array}{l}\text { Randomized, placebo- } \\
\text { controlled, double-blind study } \\
\text { (phase II clinical trial) }\end{array}$ & $\begin{array}{l}\text { 13-26 subjects with TIDM meeting the } \\
\text { inclusion criteria were randomly assigned to } \\
\text { receive daily oral verapamil or oral placebo for } \\
12 \text { months in experimental and control groups } \\
\text { respectively. }\end{array}$ & $\begin{array}{l}\text { The finding demonstrated that greater } \\
\text { improvement in insulin production (as an } \\
\text { indirect measure of beta-cell mass) in subjects } \\
\text { receiving verapamil as compared to those } \\
\text { receiving placebo would provide an indication } \\
\text { of the efficacy of this intervention. }\end{array}$ & 48 \\
\hline $\begin{array}{l}\text { Randomized double-blind } \\
\text { placebo-controlled trial } \\
\text { (phase II clinical trial) }\end{array}$ & $\begin{array}{l}\text { Oral verapamil or placebo was given for } 24 \\
\text { newly diagnosed TIDM patients with insulin } \\
\text { and endogenous } \beta \text {-cell function was assessed at } \\
\text { baseline, } 3 \text { months and I } 2 \text { months. } \\
\text { The total daily dose of insulin (TDDI) required } \\
\text { to maintain glycemic control was also analyzed. }\end{array}$ & $\begin{array}{l}\text { There was no significant difference at the baseline, } \\
\text { and the stimulated C-peptide AUC was } \\
\text { significantly larger in the verapamil group (at both } \\
3 \text { months and I } 2 \text { months). } \\
\text { At baseline, the insulin requirements were similar } \\
\text { in both groups. However, by } 12 \text { months, the TDDI } \\
\text { increased } 70 \% \text { in the placebo group whereas the } \\
\text { increase was only } 27 \% \text { in the verapamil group. }\end{array}$ & 45 \\
\hline
\end{tabular}

Abbreviations: AUC, Area under the curve; MMTT, Mixed-meal tolerance test; TIDM, Type I diabetes mellitus; TIIDM, Type II diabetes mellitus; TDDI, Total daily dose of insulin. 


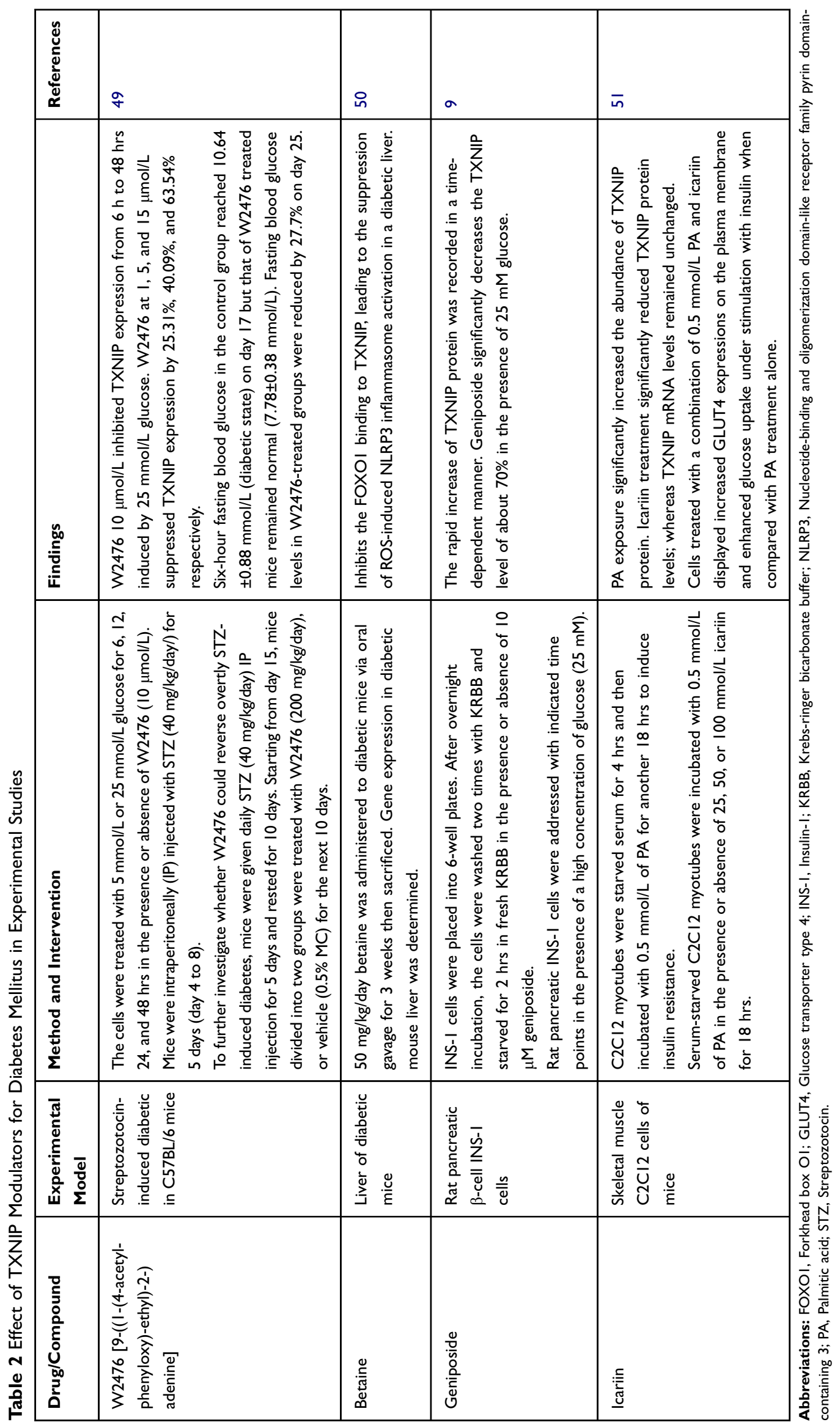




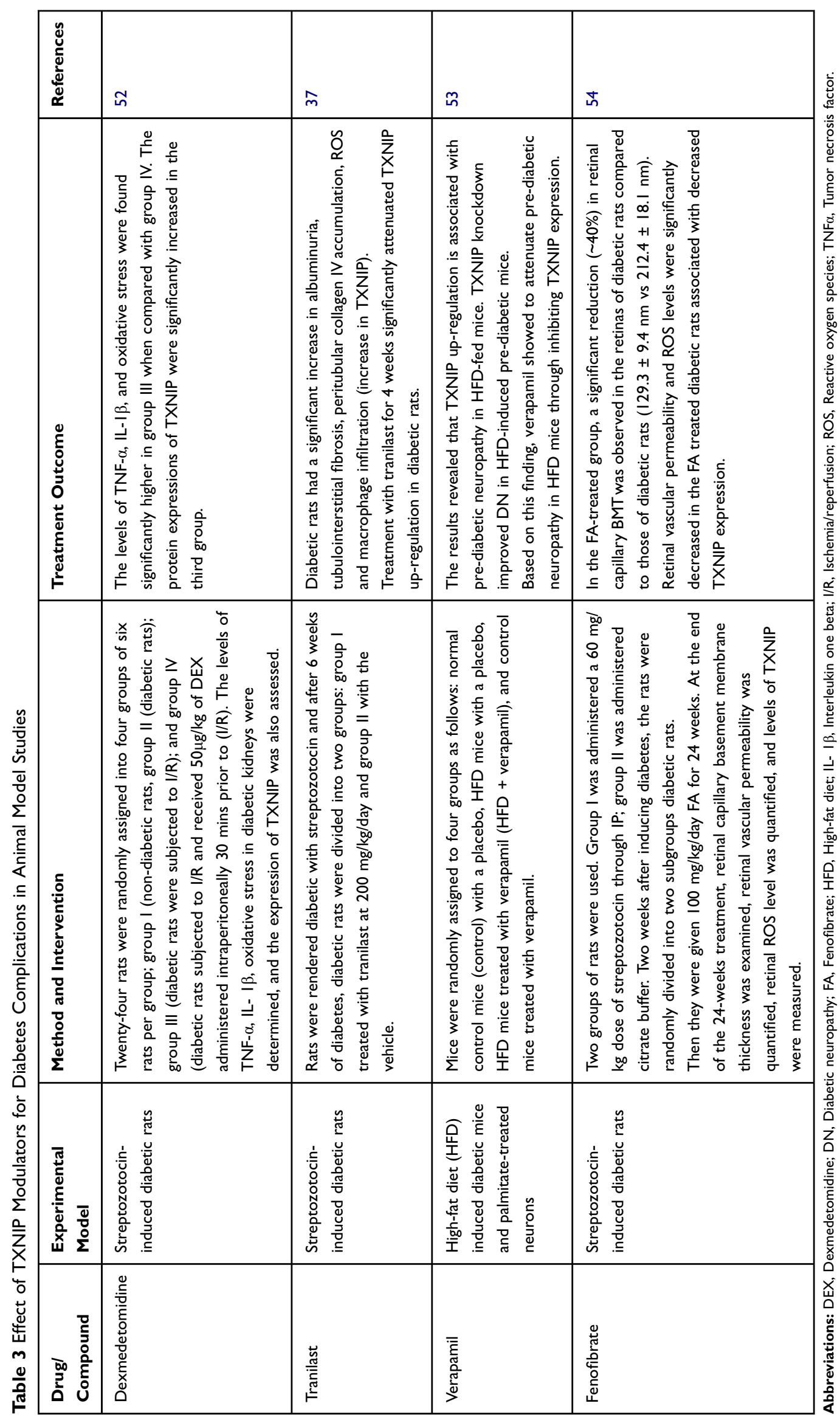




\section{Author Contributions}

All authors contributed to data analysis, drafting and revising the article, gave final approval of the version to be published, and agree to be accountable for all aspects of the work.

\section{Disclosure}

The authors declared that there is no competing interest or financial support from any institution or organization.

\section{References}

1. Okur ME, Karantas ID, Siafaka PI. Diabetes mellitus: a review on pathophysiology, current status of oral pathophysiology, current status of oral medications and future perspectives. ACTA Pharm Sci. 2017;55(1):61-82.

2. Abebe N, Kebede T, Addise D. Diabetes in Ethiopia 2000-2016 prevalence and related acute and chronic complications; a systematic review. Afr J Diabetes Med. 2017;25(2):7-12.

3. Rangel ÉB, Rodrigues CO, De Sá JR. Micro and macrovascular complications in diabetes mellitus: preclinical and clinical studies. $J$ Diabetes Res. 2019;1-5. doi:10.1155/2019/2161085

4. Ganie MA, Kotwal S. Recent advances in management of diabetes mellitus. J Int Med Sci Acad. 2012;25(3):171-175.

5. Forbes JM, Cooper ME. Mechanisms of diabetic complications. Physiol Rev. 2013;93(1):137-188. doi:10.1152/physrev.00045.2011

6. International Diabetes Federation (IDF). Diabetes Atlas. $8^{\text {th }}$ ed. Brussels, Belgium; 2017. Available from: http://www.diabetesatlas. org. Accessed August 23, 2019.

7. International Diabetes Federation (IDF). Diabetes Atlas. 7th ed. Brussels, Belgium; 2015. Available from: http://www.diabetesatlas. org. Accessed July 15, 2019.

8. International Diabetes Federation (IDF). Diabetes Atlas. 6th ed. Brussels, Belgium; 2013. Available from: http://www.diabetesatlas. org. Accessed August 17, 2019.

9. Liu C, Hao Y, Yin F, Zhang Y, Liu J. Geniposide accelerates proteasome degradation of Txnip to inhibit insulin secretion in pancreatic $\beta$-cells. $J$ Endocrinol Invest. 2017;40(5):505-512. doi:10.1007/s40618-016-0591-9

10. Forbes JM, Cooper ME. Mechanisms of diabetic complications. Physiol Rev. 2017;93(1):137-188.

11. Yoshihara E, Masaki S, Matsuo Y, Chen Z, Tian H, Yodoi J. Thioredoxin/TXNIP: redoxisome, as a redox switch for the pathogenesis of diseases. Front Immunol. 2014;4:514. doi:10.3389/ fimmu.2013.00514

12. Kampmann U, Madsen LR, Skajaa GO, Iversen DS, Moeller N, Ovesen P. Gestational diabetes: a clinical update. World $J$ Diabetes. 2017. 6(8):1065-1075.

13. Deepa D, Kiran B, Gadwalkar SR. Macrovascular and microvascular complications in newly diagnosed type 2 diabetes mellitus. Indian $J$ Clin Pract. 2014;25(7):644-648.

14. Chen J, Hui ST, Couto FM, et al. Thioredoxin-interacting protein deficiency induces Akt/Bcl-xL signaling and pancreatic beta-cell mass and protects against diabetes. FASEB J. 2008;22(10):35813594. doi:10.1096/fj.08-111690

15. Katsu-Jiménez Y, Vázquez-Calvo C, Maffezzini C, et al. Absence of TXNIP in humans leads to lactic acidosis and low serum methionine linked to deficient respiration on pyruvate. Diabetes. 2019;68 (4):709-723. doi:10.2337/db18-0557

16. Hu J, Yu Y. The function of thioredoxin-binding protein-2 (TBP-2) in different diseases. Oxid Med Cell Longev. 2018;24(5):1-10.

17. Alhawiti N, Al Mahri S, Azhar Aziz M, Shafi Malik S, Mohammad S. TXNIP in metabolic regulation: physiological role and therapeutic outlook. Curr Drug Targets. 2017;18(9):1095-1103. doi:10.2174/ 1389450118666170130145514
18. Spindel ON, World C, Berk BC. Thioredoxin interacting protein: redox dependent and independent regulatory mechanisms. Antioxid Redox Signal. 2012;16(6):587-596. doi:10.1089/ars.2011.4137

19. Gerber PA, Rutter GA. The role of oxidative stress and hypoxia in pancreatic beta-cell dysfunction in diabetes mellitus. Antioxid Redox Signal. 2017;26(10):501-518. doi:10.1089/ars.2016.6755

20. Tinkov AA, Bjørklund G, Skalny AV, et al. The role of the thioredoxin/thioredoxin reductase system in the metabolic syndrome: towards a possible prognostic marker. Cell Mole Life Sci. 2018;75 (9):1567-1586. doi:10.1007/s00018-018-2745-8

21. Chong CR, Chan WPA, Nguyen TH, et al. Thioredoxin-interacting protein: pathophysiology and emerging pharmacotherapeutics in cardiovascular disease and diabetes. Cardiovasc Drugs Ther. 2014;28 (4):347-360. doi:10.1007/s10557-014-6538-5

22. Shalev A. Minireview: thioredoxin-interacting protein: regulation and function in the pancreatic $\beta$-cell. Mole Endocrinol. 2014;28(8):12111220. doi:10.1210/me.2014-1095

23. Xu G, Chen J, Jing G, Shalev A. Thioredoxin-interacting protein regulates insulin transcription through microRNA-204. Nat Med. 2013;19(9):1141. doi:10.1038/nm.3287

24. Hwang JSH, Jeon YH. The structural basis for the negative regulation of thioredoxin by thioredoxin-interacting protein. Nat Commun. 2014;5:2958. doi:10.1038/ncomms3958

25. Mahmood DF, Hadri K, Simmet T, Rouis M. The thioredoxin system as a therapeutic target in human health and disease. Antioxid Redox Signal. 2013;19:1266-1303. doi:10.1089/ars.2012.4757

26. Schulze PC, Takahashi T, He Z, King GL, Lee RT. Hyperglycemia promotes oxidative stress through inhibition of thioredoxin function by thioredoxininteracting protein. J Biol Chem. 2004;279:3036930374. doi:10.1074/jbc.M400549200

27. Liu L, Liu Y, Qi B, Wu Q, Li Y, Wang Z. Nicorandil attenuates endothelial VCAM-1 expression via thioredoxin production in diabetic rats induced by streptozotocin. Mol Med Rep. 2014;9(6):22272232. doi: $10.3892 / \mathrm{mmr} .2014 .2066$

28. Dunn LL, Simpson PJ, Prosser HC, et al. A critical role for thioredoxin-interacting protein in diabetes-related impairment of angiogenesis. Diabetes. 2014;63(2):675-687. doi:10.2337/db13-0417

29. Li X, Kover KL, Heruth DP, et al. Thioredoxin-interacting protein promotes high-glucose-induced macrovascular endothelial dysfunction. Biochem Biophys Res Commun. 2017;493(1):291-297. doi:10.1016/j.bbrc.2017.09.028

30. Zeng J, Chen B. Epigenetic mechanisms in the pathogenesis of diabetic retinopathy. Ophthalmol. 2014;232(1):1-9. doi:10.1159/000357824

31. Perrone L, Devi T, Hosoya K, Terasaki T, Singh L. Inhibition of TXNIP expression in vivo blocks early pathologies of diabetic retinopathy. Cell Death Dis. 2010;1(8):1-11. doi:10.1038/ cddis. 2010.42

32. Singh LP, Devi TS, Yumnamcha T. The role of TXNIP in mitophagy dysregulation and inflammasome activation in diabetic retinopathy: a new perspective. JOJ ophthalmol. 2017;4(4):1-11. doi:10.19080/ JOJO.2017.04.555643

33. Duan J, Du C, Shi Y, Liu D, Ma J. Thioredoxin-interacting protein deficiency ameliorates diabetic retinal angiogenesis. Int $J$ Biochem Cell Biol. 2018;94:61-70. doi:10.1016/j.biocel.2017.11.013

34. Coucha M, Elshaer SL, Eldahshan WS, Mysona BA, El-Remessy AB. Molecular mechanisms of diabetic retinopathy: potential therapeutic targets. Middle East Afr J Ophthalmol. 2015;22(2):135. doi:10.4103/0974-9233.154386

35. Zhang WLH, AlShabrawey M, Caldwell RW, Caldwell RB. Inflammation and diabetic retinal microvascular complications. $J$ Cardiovasc Dis Res. 2011;2:96-103. doi:10.4103/0975-3583. 83035

36. Chen W, Zhao M, Zhao S, et al. Activation of the TXNIP/NLRP3 inflammasome pathway contributes to inflammation in diabetic retinopathy: a novel inhibitory effect of minocycline. Inflam Res. 2017;66(2):157-166. doi:10.1007/s00011-016-1002-6 
37. Tan SM, Zhang Y, Cox AJ, Kelly DJ, Qi W. Tranilast attenuates the up-regulation of thioredoxin-interacting protein and oxidative stress in an experimental model of diabetic nephropathy. Nephrol Dial Transpl. 2010;26(1):100-110. doi:10.1093/ndt/gfq355

38. Zhang G, Zhou L, Xu Z, Pronyuk K, Chen X, Wang H. Diabetic nephropathy: causative and protective factors. Glob J Med Res. 2015;15(2):17-26.

39. Shah A, Xia L, Masson EA, et al. Thioredoxin-interacting protein deficiency protects against diabetic nephropathy. Clin J Am Soc Nephrol. 2015;26(12):2963-2977. doi:10.1681/ASN.2014 050528

40. Xu LW, Jimin L, Yingying C, Yaoming X. TXNIP mediated the oxidative stress response in glomerular mesangial cells partially through the AMPK pathway. Biomed Pharmacother. 2018;107:785792. doi:10.1016/j.biopha.2018.08.067

41. Cha-Molstad SG, Chen J, Shalev A. Glucose-stimulated expression of Txnip is mediated by carbohydrate response element-binding protein, p300, and histone $\mathrm{H} 4$ acetylation in pancreatic beta cells. J Biol Chem. 2009;284(25):16898-16905. doi:10.1074/jbc.M109.010504

42. Fang SJY, Zheng H. High glucose condition upregulated TXNIP expression level in rat mesangial cells through ROS/MEK/MAPK pathway. Mol Cell Biol. 2011;347(2):175-182.

43. Yu FX, He H, Hagen T, Luo Y. Thioredoxin-interacting protein (TXNIP) gene expression: sensing oxidative phosphorylation status and glycolytic rate. J Biol Chem. 2010;285(33):25822-25830. doi:10.1074/jbc.M110.108290

44. Cherney TK. Beta-cell preservation in patients with type 1 diabetes. Nat Med. 2018;24:1089-1096. doi:10.1038/s41591-018-0144-1

45. Ovalle F, Grimes T, Xu G, et al. Verapamil and beta-cell function in adults with recent-onset type 1 diabetes. Nat Med. 2018;24(8):1108 doi:10.1038/s41591-018-0089-4

46. Xu G, Chen J, Jing G, Shalev A. Preventing $\beta$-cell loss and diabetes with calcium channel blockers. Diabetes. 2012;61(4):848-856. doi: $10.2337 / \mathrm{db} 11-0955$
47. Yin T, Kuo SC, Chang YY, Chen YT, Wang WK. Verapamil use is associated with reduction of newly diagnosed diabetes mellitus. $J$ Clin Endocrinol Metab. 2017;102(7):2604-2610. doi:10.1210/ jc.2016-3778

48. ClinicalTrials.gov. Verapamil for beta-cell survival therapy in type 1 diabetes. Available from: https://clinicaltrials.gov/ct2/show/results/ NCT02372253. Accessed November 17, 2019.

49. Li T, Lin G, Zhong L, et al. W2476 ameliorates $\beta$-cell dysfunction and exerts therapeutic effects in mouse models of diabetes via modulation of the thioredoxin-interacting protein signaling pathway. Acta Pharmacol Sin. 2017;38(7):1024. doi:10.1038/aps.2017.15

50. Kim DH, Kim SM, Lee B, et al. Effect of betaine on hepatic insulin resistance through FOXO1-induced NLRP3 inflammasome. J Nutr Biochem. 2017;45:104-114. doi:10.1016/j.jnutbio. 2017.04 .014

51. Li M, Zhang Y, Cao Y, et al. Icariin ameliorates palmitate-induced insulin resistance through reducing thioredoxin-interacting protein (TXNIP) and suppressing ER stress in C2C12 myotubes. Front Pharmacol. 2018;9:1-12. doi:10.3389/fphar.2018.01180

52. Yeda X, Shaoqing L, Yayi H, et al. Dexmedetomidine protects against renal ischemia and reperfusion injury by inhibiting the P38MAPK/TXNIP signaling activation in streptozotocin-induced diabetic rats. Acta Cir Bras. 2017;32(6):429-439. doi:10.1590/s0102865020170060000003

53. Xu L, Lin X, Guan M, Zeng Y, Liu Y. Verapamil attenuated prediabetic neuropathy in high-fat diet-fed mice through inhibiting TXNIP-mediated apoptosis and inflammation. Oxid Med Cell Longev. 2019;2019:1-14.

54. Li J, Wang P, Chen Z, Yu S, Xu H. Fenofibrate ameliorates oxidative stress-induced retinal microvascular dysfunction in diabetic rats. Curr Eye Res. 2018;43(11):1395-1403. doi:10.1080/02713683.2018.1501072

Diabetes, Metabolic Syndrome and Obesity: Targets and Therapy

Dovepress

\section{Publish your work in this journal}

Diabetes, Metabolic Syndrome and Obesity: Targets and Therapy is an international, peer-reviewed open-access journal committed to the rapid publication of the latest laboratory and clinical findings in the fields of diabetes, metabolic syndrome and obesity research. Original research, review, case reports, hypothesis formation, expert opinion and commentaries are all considered for publication. The manuscript management system is completely online and includes a very quick and fair peer-review system, which is all easy to use. Visit http://www.dovepress.com/testimonials.php to read real quotes from published authors.

Submit your manuscript here: https://www.dovepress.com/diabetes-metabolic-syndrome-and-obesity-targets-and-therapy-journal 